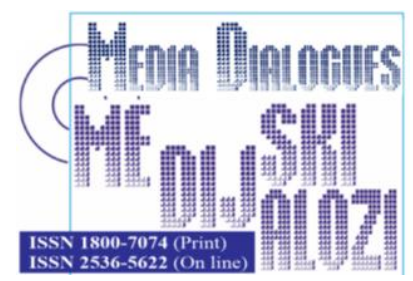

Brautovic, H., Milosavic, M. (2020), „Entertainment Public Relations Agencies and Their Web Sites", Media Dialogues / Medijski dijalozi,

Vol. 14, No. 2, pp. 7-20.

\title{
Entertainment Public Relations Agencies and Their Web Sites
}

\section{HELENA BRAUTOVIC,}

University of Dubrovnik,

Croatia

\author{
MIA MILOSLAVIC, \\ University of Dubrovnik, \\ Croatia
}

\begin{tabular}{|c|c|}
\hline$A \boldsymbol{R} \boldsymbol{T} \boldsymbol{I C L} \boldsymbol{E}$ & Received: November 14, 2019 / Revised from: December 14, 2019 \\
$\boldsymbol{I} \boldsymbol{N} \boldsymbol{F} \boldsymbol{O}$ & Accepted: January 15, 2020 / Available online: October 15, 2020 \\
\hline DOI & doi.org/10.14254/1800-7074/13-4/1 \\
\hline
\end{tabular}

\begin{abstract}
In this paper a sector of $P R$ that is relatively new in Croatia, the entertainment $P R$ web sites will be analyzed. The web site analysis is based on two main criteria: content and design. Entertainment PR agencies are almost nonexistent in Croatia, so this paper focuses entirely on three agen- cies in the United States: PR Entertainment, Rogers \& Cowan and Serge Entertainment. All agencies were chosen at
\end{abstract}


random, but are backed by good references. Of all three, Rogers \& Cowan is specifically considered to be among the best in the Entertainment PR industry.

KEYWORDS: Entertainment $P R$, web sites, PR entertainment, Rrogers \& Cowan, serge entertainment, Communications.

\section{INTRODUCTION}

Entertainment PR has grown more sophisticated since its early days. Today publicists for major stars hold highly powerful positions. For example, one leading Hollywood press agent, Pat Kingsley, controls access to more than ninety stars, including Julia Roberts, Woody Allen, and Michelle Pfeiffer. Kingsley rejects journalists' requests more often than she accepts them. Her explanation: "It's not our job to give the press everything they want" (Mogel, 1993, p. 109).

Entertainment PR commonly involves tie-ins. When you see a celebrity on the cover of a popular magazine, they have likely recently released a movie. Publicists who work for celebrities can decide which magazine gets an exclusive and select all the people to work on the story, providing an ideal situation for negotiation. Entertainment PR people act as spokespeople for clients, which often involve mitigating incidents. Apart from using crisis communication to repair their client's damaged images, their job also includes writing press releases, sending them to the media and calling the media to encourage them to write a certain story. They are also in charge of setting up interviews and creating guidelines for their clients and the ways they deal with the media.

Entertainment PR may seem like a glamorous field, and in some respects it is. However, it is also very stressful and highly competitive (Mogel, 2000, p. 302). What often constitutes stressful situations for PR agents is very newsworthy information for the media, primarily in the form of gossip. Besides movie stars, other highly discussed members of society include successful athletes, TV personalities - talk show hosts and politicians. Sometimes public interest in these personalities is a simple result of public curiosity but it is often nurtured by publicists. The publicity buildup of individuals is separate from mainstream public relations work, so some professional practitioners are embarrassed by the exaggerations and tactics used by promoters of so-called "beautiful people." (Wilcot, 2003, p. 452). Nevertheless, all PR professionals could benefit from familiarizing themselves with personal publicity techniques.

A personal publicist bears special responsibilities. Their clients often seek personal advice, especially during crises. A publicist's responsibilities are not only to protect clients from bad publicity but also to generate positive news. When a client gets in trouble due to irresponsible behavior, PR people are in charge of the damage control. Most often they write statements of regret that clients go public with. 
Anticipating all possible problems and maintaining a client's public image involves running a campaign to create public awareness of an individual like interviewing the client, preparing a background (biography), devising a marketing strategy and organize PR releases, photos, public appearances, essentially creating a lot of buzz.

Another form of Entertainment PR is event promotion, which is similar in several ways to personal publicity. To accomplish this, motion picture studios, television production firms, and networks often apply the principle of "drip-drip-drip" publicity. In other words, there is a steady output of information about a certain production (Ibid., p. 461).

Entertainment PR also involves product placement in movies. Moviegoers are frequently exposed to publicity projects in the films they watch, although they are rarely aware of it. Public relations specialists who arrange coverage of their clients' products or causes in movies help their clients obtain high visibility because Hollywood motion pictures are often seen by millions of viewers (Ibid., p. 535).

\section{ROGERS \& COWAN, PR ENTERTAINMENT AND SERGE ENTERTAINMENT}

Founded in 1935, Rogers \& Cowan is a pioneering PR firm specializing in the Entertainment PR industry. As mentioned previously, the firm was founded by Henry Rogers. Warren Cowan joined the firm and his mentor (Rogers) in 1946 and by 1950 was made partner, changing the firm's name to Rogers \& Cowan. Rogers \& Cowan quickly became the biggest entertainment PR firm in the world. With a list of clients that looks like the entertainment industry's "Who's Who", Cowan represented some of the biggest stars of the late 20th century. For example: Paul Newman, Elizabeth Tay- lor, Kirk Douglas, Frank Sinatra, and Elton John. Today Hollywood celebrity clients include Sylvester Stallone, Kevin Costner, Bruce Willis, John Travolta and Tom Cruise. (http://en.wikipedia.org/wiki/Warren_Cowan).

This firm was the first to organize celebrity charity-fundraisers, including the first pro-celebrity sports event (a golf tournament in 1950). Rogers also pioneered Hol- lywood's Academy Awards campaigns, beginning with Joan Crawford and her role in Mildred Pierce (1945). The buzz he created through her campaign helped her win the Best Actress Oscar. In 1997, Cowan personally introduced the little-known Italian actor Roberto Benigni to his famous American peers, all of them Cowan clients and Academy voters. That year Benigni and his picture, Life Is Beautiful, won three Oscars (http://en.wikipedia.org/wiki/Warren_Cowan).

The company remained successful over the years, but in 1988, it was sold to English conglomerate Shandwick Plc. But the change in the own- ership made no difference in service quality so Rogers \& Cowan are still one of the leading PR com- 
panies in entertainment industry. The difference is that now the company has two offices in London, making international operating much easier.

PR Entertainment Inc. was founded in 2002 by Paul Reder, the former Vice President of Entertainment for Caesars Entertainment, Inc. /Park Place Entertainment, formerly the largest gaming company in the world. PR Entertainment Inc. now serves as an outsource vendor for several major hotels and casinos worldwide. They offer complete consulting services, from short - term site visits to long-term management contracts. The company has become one of the fastest growing PR firms in recent years thanks to its services such as contract negotiations, ticket sales, box office ser- vices, talent strategies, production, marketing, advertising, and administration. The company's long list of clients includes celebrities Julio Iglesias, Bad Company, Billy Ray Cyrus, Coco Montoya, Deep Purple, Jay Leno, Ray Charles, Scorpions, Van Morrison, and the Village People. This client list is consistent with the company's motto: "Our sincerest mission is to aid our clients in maximizing their potential to the fullest by creating and seizing opportunities. We believe in a three - prong formula for success - regularly performing at world- class venues, investing sufficient time to fre-quently engage in the creative process and pursuing film and television appearanc- es." - : http://www.prentertainment.net/index.php?otion=com_ content $\&$ view $=$ article $\& i d=50 \&$ Itemid $=55$.

Serge Entertainment PR is part of the Serge Entertainment group specializing in the fields of entertainment, music management, and public relations for bands and artists. The company provides media access to many of the music industry's top publishers, editors and journalists, including Features Music Morsels Magazine, talent, industry showcase, and more. They also represent individual artists such as Bad Boy, Mark Birmingham, Lea Brennan, and Prince EQ, Cryptic Vision, Erik Norlander, Def Leppard, Jack Foster III, Steve Walsh, I-Am-Unlimited Records, Right to Rock, Holly Allen and Alyssa.The company's stellar track record in the music industry is recognized worldwide. Serge Entertainment has been in the music business for several decades and offers a great number of services including marketing, sponsorship, advertising campaign planning, copy and layout print, broadcast and direct mail, press releases, publicity programs, Internet marketing, and special event planning.

Consultant and company CEO Sandy S. Serge works with musicians and songwriters around the world. As a PR specialist, she oversees all aspects of the company's work involving clients. Few in the business today can combine her grasp of the music industry from performance to production to management to public relations. Even more importantly, she focuses on the highly specialized field of publicity and utilizes her successful, award-winning music trade publication Music Morsels(C) as a vehicle to reveal exceptional music to the world (http://www.serge.org/division/ PublicRelations/ our_team.htm). 


\section{ANALYSIS OF THE WEB PAGES OF THE PR AGENCIES}

\subsection{Rogers \& Cowan web page analysis}

The Rogers \& Cowan's web page is minimalist and well organized, easy to navigate. A logo on top of the page links to the home page. Several pages have the quotations related to content of the each page. Two featured quotes on the home page read: "The difference between creating awareness and changing the way people think" and "Managing clients at the intersection of entertainment, technology and consumer marketing". A search engine is located on the left part of each page and every subcategory. Next to the logo is a navigation section with three options: Agency, Expertise and Contact.

The first option, Agency, has five subcategories: Overview, News, Awards, Careers/ Internships, and FAQ's. The first subcategory is Overview, summarized by the quote on the left side of the page: "We are adept at maximizing media opportunities for our clients". The Overview section's purpose is to explain the agency's way of operating as well as to make sure the company's guidelines are clear. It also mentions the team's experience, relations with clients, and provides a short service explanation.

The second subcategory is News, which features all news related to the company and its staff. The latest updates include naming the new senior vice president, handling worldwide publicity for the Bahamas International Film Festival, naming the executive vice president etc.

The third subcategory of the Agency section is Awards. Rogers \& Cowan's creative team has always been known for innovation and the company's achievements provide brand recognition in the public relations industry. Examples of their award winning campaigns are: the Publishers Clearing House Prize Patrol Blitz (Silver Anvil), the Vanilla Coke Launch and TiVo (both Platinum PR Award), the Grammy Awards and Soul Train Awards (PCLA Pro Award), Ray - Ban: The Ultimate Hollywood Accessory (SABRE), the NapsterToGo Launch (PRSA PRISMS), the launch of the Five Browns Self-Titled Debut Album (Bulldog Award) and many others. All 40 awards for these campaigns presented by 12 different award organizations are listed on the page.

The fifth subcategory is Careers/ Internships. Career Opportunities are said to be a pathway to success. The page explains employee expectations and details what the company has to offer. It also mentions that the senior leadership is among the most respected in the entertainment PR industry. A special Internship Section explains how these positions are intended to provide a true learning experience as well as give students a chance to observe PR professionals in a business environment. An intern's responsibilities are to assist to the publicists with every day duties. Roger \& Cowan are currently accepting students from both Los Angeles and New York and E-mail addresses for both offices are clearly listed on the page. 
The last subcategory of the Agency section, FAQ's, offers answers to five questions: "What types of clients do Rogers \& Cowan represent, What types of services does the agency provide, Who works at $R \& C$, Where can you find Rogers \& Cowan and What are the next steps I should take?". The second option in the navigator bar is Expertise and has four subcategories: Entertainment content, Corporate \& Consumer Marketing, Integrated Marketing Solutions, and Consumer Technology. Each of these also has its own subcategories.

The first one, Entertainment content, has six: Film, Television/ DVD, Music, Arts/ Culture, Video Games, and Talent. The film section contains a quote "We make movies MUST SEE MOVIES" which accurately summarizes their services. But offering to help make the public aware of a movie, making unknown independents into block- busters, and providing an edge at top film festivals worldwide are just part of the film related services listed on the web page.

The Television/DVD quote: "In TV, the eyes have it, we help deliver them" explains the company's view on TV today. They also specify that "talent and home entertainment expertise delivers all important market integration and long term publicity reach to all our television clients".

Music is the third subcategory of the Entertainment content and features a quote: "Great music DESERVES great Media coverage" which simply explains the agency's main goal. They also mention that Rogers and Cowan represents the top award shows in the United States.

The Arts/ Culture section contains details about the quality and consistency of what the agency offers for all clients. It says "our team can tap into the global resources of an international public relations network to create targeted and integrated campaigns that deliver a message of quality and prestige to a wider audience". Their team specializes in classical music and performing arts.

The Video Games section contains this quote: "You Let the Games Begin, We'll set the stage" which explains the company's connection with developers, pub- lishers and associations in the country. Rogers \& Cowan represent some of the biggest brands in interactive entertainment. Talents is the last subcategory in the Entertainment content. The quote "Celebrities AREN'T JUST LIKE brands. They are brands." encapsulates the company's philosophy. They also clearly state that their expert team can take care of any PR service celebrities might request.

The second subcategory under Expertise is Corporate \& Consumer Marketing and has five subcategories of its own: Consumer Products, Media/ Publishing, Fashion/ Beauty/ Lifestyle, Sports Marketing, and eMedia. The first one, Consumer Products contains a quote: "Rogers \& Cowan DEFINES, DIFERENTIATES, and DELIVERS". This represents the company's specialty in delivering the cool factor to mass-market brands and multi - faceted marketing campaigns. 
The Media/ Publishing section features the following quote: "Public Relations FOR THE BOOK - not by the book". This means that publishing publicity is about more than parties, although they do organize those very well. Their customers include many of the world's best selling authors, mostly due to the creative team's ability to combine old and new marketing techniques specifically suited to their clients.

The Third subcategory of Corporate \& Consumer Marketing is Fashion/ Beauty/ Lifestyle and highlighted by this quote: "The beauty is in the EYE OF THE BEHOLDER. We deliver the beholders". The company represents A - list celebrities and therefore promise to create A - list campaigns. This page introduces Rogers \& Cowan's Film Fashion Unit that delivers client's products to celebrity stylists. Film Fashion is an exclusive division of the company and has a direct link to the site.

"Teamwork isn't something THAT JUST HAPPENS on the field" is the main quote for the next subcatgory, Sports Marketing. This division focuses on increasing year to year media and attendance growth for key women's sports properties. The page also explains how an alliance with Octagon Wordwide is used to tap into the sponsorship and marketing resources of one of the largest sports marketing companies in the world.

The last subcategory of Corporate \& Consumer Marketing, eMedia, is said to be evolving every day. This page explains how possessing the expertise to create new media campaigns, helps establish brands. Their use and knowledge of the Internet are also explained in detail.

The third subcategory of Expertise is Integrated Marketing Solutions, comprised of four parts: Product Placement, Influential Seeding, Promotions, and Events/ Tradeshows. The Product Placement's quote reads: "If we place it - THEY WILL COME". This means that the company will get the targeted audience to notice the clients' product. They also claim that when a new product is released, they can provide full publicity support.

The second subcategory, Influential Seeding, explains the company's philosophy on long-term brand strategy by seeding targets that maintain a product's cool factor even as it enters the mass market. The quote on this page is: "Leveraging celebrity INTELLIGENTLY". The team is introduced as the most prolific and successful seeding facilitator in Hollywood.

Promotions - is the third subcategory of Integrated Marketing Solutions. It reveals Rogers \& Cowan's success formula: "CREATIVITY + CONNECTONS = Great Promotions". The page explains that entertainment event and award show connections are a doorway to great strategic promotions for a company's clients. The aim is simple - to multiply message impact for a target audience.

The last Integrated Marketing Solutions subcategory is Events/ Tradeshows. The page details how the professional team can leverage its extensive entertainment 
resources to generate critical mass regional and national media exposure. The quote says: "We turn YOUR EVENT into the MAIN EVENT".

The last subcategory of Expertise is Consumer Technology, and it has four subcategories: Convergence, Digital Entertainment, Video Games, and eMedia. Convergence explains how the company's expert team creates innovative campaigns for clients. The client roster is filled with influential names -brand technology innovators in the world. The quote reads: "The Best Technology KEEPS IT SIMPLE - So Does the Best PR".

"Everything Has GONE DIGITAL - Including PR" is the quote on the Digital Entertainment page. Rogers \& Cowan claims to be an active member of the entertainment industry guilds and associations that constantly debate the policies and practices governing how content will be manipulated and distributed in the digital era. This page explains how this department's staff is able to react quickly to all technological trends.

The Video Games link is to the same information as the Entertainment Content page and eMedia links to the same information as Corporate and Consumer Marketing. The last option on the main menu is Contact with only two subcategories: US Offices and International Offices. The two US offices are in New York and Los Angeles and this page supplies the office addresses and e-mail address of the chief executive officer Tom Tardio. There is also an option to enter all data (for potential clients) to send to the company. Both International Offices are located in London. Addresses listed include one for Entertainment PR \& Consumer Marketing and its Account Director Emma McCorkell, and one for Product Placement and its Account Manager Kate Abrey.

\subsection{PR Entertainment web page analysis}

The first impression of PR Entertainment's web page is that it is overwhelming. It has two menus, two slideshow windows with information, and a slideshow banner beneath the main menu. The top of the page contains the company's logo that links to the home page. The main menu is located just beneath the company's logo and consists of the following pages: Home, About, Divisions, Project, Client Roster, Con- tact, Upcoming shows, and Fixion images.

On the left side of the page is the second menu, which consists of five visual-lydivided boxes: Divisions, Client Roster, Consulting, Projects and About Menu. In the center of the page is a slideshow window that has six different information slides. On the right side of the window is a navigation bar with all six slides listed. On the bottom of the page is the second slideshow window that has just one picture that moves inside of the window. 
The placement of the main menu just beneath the company's logo and the other menu on the left side of the page is a little confusing. But when examined more closely it becomes apparent that the menu on the left side draws attention to information that may interest potential clients, and easily visible access makes it procurable. As mentioned above, the first option on the main menu is Home, linked to the home page. About is the second option with three subcategories: Staff, References, and News. Staff has background information and E-mail addresses of only two people: Paul Reder (the founder) and Michael Swift (Manager of the Sporting Events division).

The second subcategory of the About option is References. All references are addressed to Paul and explain how great it is to work with him. For example: "It is, was and will always be a pleasure to deal with Paul. He is knowledgeable, street wise and has a grasp of many different genres of music in the live music marketplace today. He was always extremely organized and that seemed to trickle down to his staff, who was also always extremely professional. To me this was a reflection of the way he conducted himself personally and professionally. I hope to be doing business with again very soon. As overall head of the concert division here at APA and the executive vice president of the company, it was a nice feeling to know that any client I sold to him would be presented in the best possible circumstances." (Nat Burgess, Head of Concert Division and Executive Vice President, Agency for the Performing Arts (APA) - http://www.prentertainment.net/index.php?option=com_content\& view $=$ article $\& i d=48 \&$ Itemid $=62$.

The third subcategory, News, is still a work in progress and is labeled as "Coming soon". Divisions, the third option on the main menu navigation bar, has six subcategories: Concerts/ Headline, Producer/ Production, Sporting Events, Artist Rep, Entertainment, and Nightclub. Concerts/ Headline focuses on the experience of PR Entertainment Inc.'s staff, the quality of services they offer, and their team's abilities. There is a Contact Us link on the bottom of the page.

The second subcategory is Producer/Production, which lists several exclusively represented live Production Show producers from around the world. These include: The Magic of Joseph Gabriel, The Chipper Lowell Experience, TV's Magic Stars, and The Kinsey Sicks, each linked to its own page with more information. On the bottom of the page is a list of more productions with links to their web sites. The page also specifies the firm's ability to create stage spectaculars.

On the top of the Sporting events page is a box that links to the TKO Boxing page (which I will describe later on). Beneath that is a list of "representative sampling of the events created, produced or promoted" by the PR Entertainment team. The list has 14 categories: boxing, volleyball, golf, tennis, hockey, soccer, professional wrestling, television, horse racing, motorcycle jumping, figure skating, professional bowling, sumo, and miscellaneous. Each of the categories lists finished events. 
Artist rep, the fourth subcategory of Divisions, says: "The Exclusive Artist Representation and Development Division of PR Entertainment, Inc., proudly features some of the most talented comedic performers in the country." The page also describes the firm's approach to building careers, and its mission to maximize client's potential. The bottom of the page contains a link to the Client Roster.

The Entertainment section contains basic information about PR Entertainment Inc. including services, fields of expertise, and an additional emphasis on the team's quality. The last subcategory of Divisions is Nightclub. The top of the page contains four categories: Nero's Nightclub, Blu Nightclub, Opal Nightclub, and Opal St. Maarten. When opened, each category has a picture of the nightclub and the exact location. Beneath that is slideshow window that features pictures of all the nightclubs. The company has been involved in the concepts, designs, and management of nightclub projects worldwide and has over 20 years of experience in the nightclub industry.

The fourth option on the main menu is Projects, with two subcategories: Current Projects and Shows Produced. Current Projects contains six articles: Aonix " $A$ Journey of Mysticism", Paul Oakenfold, Chelsea Handler, James Van Praagh, Sylvia C. Browne, and Fixion Images. Each of the categories has an option to link to a page with more information about all the projects.

Shows Produced has a list of all shows that were produced by PR Entertainment Inc.: Aga-Boom, Beijing Circus, Carnival of Wonders, Chicago - The Musical, Chinese Acrobats, The Corey Schmidt Experience, Cirque Ingenieux, Dance2Xtreme, Illusionarium, Jubilation, Little Shop of Horrors, Melinda - First Lady of Magic, Montreal Ice Ballet - Zigra, Passion X-treme, Peking Acrobats, Stomp, The Nutcracker, and Thun- der From Down Under.

The fifth option on the main menu is Client Roster, and it has four subcategories: Comedy, Headliners, Production Shows, and Confirmed Artists. The first subcategory, Comedy, only has a name with a link and a picture of Heather McDonald. The link leads to a page with information about her. Headliners, the second subcategory, has six boxes: Paul Oakenfold, James Van Praagh, Dr. Drew Pinsky, Sylvia C. Browne, Bill Rancic, and TKO Boxing. All the boxes are linked to articles with more information about these clients and projects.

The third subcategory is Production Shows. Client resumes make up an impressive collection of shows: major hotels, casinos, corporate events and theaters around the world have presented the works of PR Entertainment Inc. The page features a comprehensive list of Production Shows Produced and booked by Paul Reder, and PR Entertainment, Inc. for venues around the U.S.: Fusion, Fusion 2, Viva Vaudeville, Forbidden Vegas, David Brenner, Westin Las Vegas, and Quicker than the Eye, Westin Las Vegas. The last subcategory of Client Roster is Confirmed Artists. It is a list of all the clients that have a contract with PR Entertainment Inc. 
The sixth option in the main menu is Contact. It has the addresses and phone numbers of the two company offices: one in Nevada and the other in Los Angeles.

The seventh option is Upcoming Shows. It contains information about all upcoming events through the end of the year. It also gives visitors the opportunity to buy tickets online and see when and where shows will be held.

Fixion Images has a link to a separate web site also named Fixion Images, which a DVD (fractal video wallpaper/ presentation) describes as "A new realm in Video wallpaper". The page features background information about Fixion Images and explains the company's relation to Paul Reder and PR Entertainment. This is the last option on the main menu. The second menu, located on the left side of all pages, has six boxes: Divisions, Client Roster, Consulting, Projects, and About Menu. All subcategories listed in the boxes are linked to the same ones as those on the main menu.

\subsection{Serge Entertainment web page analysis}

Serge Entertainment's web page is quite plain and features two main colors: dark purple (background) and yellow (letters). Instead of a logo there is only a title "Serge Entertainment Public Relations" written in two shades of yellow. The main menu is located on the left side of the page and consists of ten categories: PR Home, Our Services, Testimonials, Internet Marketing, Our Team, Our Network, Clients, General Fees, Tour Publicity, and Serge Home. In the center of the page are short marketing messages about Serge Entertainment. For example: "The honest PR people - no spin, no speculation; only the raw facts and the naked truth." Beneath that is a link to Serge Entertainment's blog, written by Sandy Serge (CEO), which contains news, accomplishments, and happenings at the company. The bottom of the page contains contact information - address, web address, e-mail, and phone number, and it is the same on every page.

The first option in the menu, PR Home, is a link to the Home page. Our Services, the second option, discusses the PR system and focus. It also lists all services and explains the company's advantages.

The third option in the menu is Testimonials containing 21 testimonials from respected people in the industry: Erik Norlander, Owner of Think Tank Media, an independent record label, Scott Turner, producer/publisher/hit songwriter and Owner of Buried Treasure Music, Captain Kidd Music, Scott Turner Productions, John Moossa of the band MOOSSA etc. An example: "We found Serge Entertainment/Public Relations to be very thorough and professional in their PR campaign for Full Moon Bay. They took a brand new unknown group and got us reviews in several publica- tions, which really helped our credibility with both the music industry and with con- sumers. We were very impressed with Serge PR's positive 
energy, their creativity, and most important of all, their relentless follow-up" - Robert Hauver, President, Hudson Valley Records.

The fourth option in the menu is Internet Marketing. This page describes the company's ability to design campaigns especially for the Internet: E-zine possibilities, Online Radio research, music site uploads, banners, press releases, creating blogs for clients etc. Using Online Retails, the company reaches clients' audience globally by placing their $\mathrm{CD}$ in selected online retailers. The page also explains fees: "Our internet marketing campaigns are currently $\$ 750$ for a three month campaign plus expenses. Expenses include FedEx overnight delivery fees and postage for mailing press kits."

The fifth option is Our Team. It summarizes Sandy Serge's background and all her duties at the firm. It also has information about Senior Publicist Mark Waterbury, and Internet Marketer Dee Price. As for the part - time crew a quote states: "SEPR often times hires a variety of interns, scouts and part-timers to assist with projects on an as needed basis. We also have several experienced part-time booking agents on board to help form our network throughout the world."

The Our Network section lists several contacts divided by publications, radio, television and radio, club/ casino/ venue booking agents, festival booking agents, concert promoters/ booking agencies, college booking agents, corporations/ sponsorships/ endorsements, film/ TV/ advertising/ publishing/ producers, record labels, retail/ distributors, and artist managers.

The seventh option in the menu is Clients. It contains the list of select representation of the company's past and present clients. The additional option General Fees quotes prices for certain services: General Campaign, Fees: \$50/hour plus expenses, Minimum: 10 hours per month ( $\$ 500 /$ month plus expenses), Recommended: 25 hours per month (\$1250/month plus expenses)" and payment terms. The ninth option is Tour Publicity. This is considered to be the most valuable asset for creating public awareness about clients' shows. The page lists certain fees and explains techniques for alerting the media about the client. It also details methods for organizing campaigns that help to expand a brand to new market. The last option in the menu is Serge Home and it links to the home page of the Serge Entertainment Group.

\section{CONCLUSION}

Considering that Entertainment PR agencies are nonexistent in Croatia, this paper focuses on the evaluation of three agencies: Rogers \& Cowan, PR Entertainment and Serge Entertainment. The web sites of the chosen agencies seemed to follow no rules for a standard web site look. The analysis was divided in two sections, one for content and one for design. When analyzing content, I found that only Rogers \& Cowan followed any rules and contains all necessary elements for a quality web site. Alt- hough several sections of Entertainment PR's web site are still in development, 
overall the site was average. Serge Entertainment's web site on the other hand was confusing and hard to navigate. The main page contains a good amount of irrelevant information mixed up with important information. This makes the site appear very disorganized and irritating to navigate.

My web site design analysis also proved Rogers \& Cowan to be the best overall page. Their site is extremely easy to navigate and all the information is divided into logical categories. The design is a little abstract but the Hollywood theme is easy to recognize. Entertainment PR's web site is a little overwhelming. It has three slide show windows that fight for attention and the format of two navigation bars with the same links is pointless. Serge entertainment falls into last place for its web site quality. The purple background with yellow letters is pretty to look at, but very hard to read. A particularly dysfunctional design is the location of all the information in one place; subcategories would make navigation much easier.

By analyzing the web sites' content and other details, I concluded that all agencies, even those in the same industry, don't necessarily do the same work. Rogers \& Cowan is more of a Hollywood oriented agency. Their focus is on movie stars and their projects. On the other hand, Serge Entertainment is completely focused on the music industry. The agency's web site leaves no doubt that everything is about music. PR Entertainment falls somewhere in the middle--- they focus on movie stars as well as music. But this agency also specializes in all kind of entertainment shows. The conclusion is that all agencies do operate in the Entertainment industry but do not do the same work. Each agency has its own field of expertise. Accordingly, each agency's web site is created to fit the entertainment role the agency chooses. An analysis of content and design showed that Rogers \& Cowan is the most professional site, and Serge Entertainment still has a lot of work to do.

\section{LITERATURE}

Mogel, L. (1993), Making it in public relations: an insider's guide to career opportunities, Collier Books, New York.

Mogel, L. (2000), Careers in communication and entertainment, Simon \& Schuster, New York.

Wilcot, D. L., Cameron, G., Ault, P., Agee, W., Benigni, V. (2003), Public Relations: strategies \& tactics, Pearsons Education, Boston.

\section{Internet}

Warren Cowan, URL: http://en.wikipedia.org/wiki/Warren_Cowan, May 10th, 2009, 18:02

PR Entertainment's official site: http://www.prentertainment.net/index.php? option=com_content $\&$ view $=$ article $\& i d=50 \& I t e m i d=55$, May 10th, 2009, 20:19 
Serge Entertainment's official site: http://www.serge.org/division/Public Relations/our_team.htm,

PR Entertainment's official site: http://www.prentertainment.net/index. php?option=com_content\&view=article \&id=48 \&Itemid=62 